\title{
Effects of Calcium Lignosulfonate and Silicic Acid on Ammonium Nitrate Degradation
}

\author{
Ahmet Ozan Gezerman and Burcu Didem Çorbacioglu \\ Department of Chemical Engineering, Faculty of Chemistry-Metallurgy, Yildiz Technical University, 34210 Istanbul, Turkey \\ Correspondence should be addressed to Ahmet Ozan Gezerman; ahmet_ozan@yahoo.com
}

Received 24 November 2013; Accepted 18 December 2013; Published 5 February 2014

Academic Editor: Marinos Pitsikalis

Copyright (C) 2014 A. O. Gezerman and B. D. Çorbacıoglu. This is an open access article distributed under the Creative Commons Attribution License, which permits unrestricted use, distribution, and reproduction in any medium, provided the original work is properly cited.

\begin{abstract}
Ammonium nitrate salts are the most commonly used nitrogenous fertilizers in industry. However, storage of ammonium nitrate is problematic, since its initial properties can decline because of environmental factors, leading to large economic losses. In this study, in order to prevent the caking and degradation of ammonium nitrate, an alternative composition with additional calcium lignosulfonate and silicic acid was studied. The resulting fertilizer was analyzed by screening analysis, ion chromatography, and electron microscopy methods.
\end{abstract}

\section{Introduction}

The market demand for nitrogenous fertilizers such as ammonium nitrate continues to increase, and production has kept pace accordingly. In fact, ammonium nitrate has several different applications spanning multiple industries. However, its storage presents difficulties because of its sensitivity to moisture, air temperature, and the pressure exerted by the fertilizer bulk, and so manufacturers are searching for new storage solutions. Surface reactions such as crystal bridges, surface diffusion, and van der Waals interactions lead to caking problems [1]. Therefore, in order to improve the surface features of ammonium nitrate fertilizers, chemical conditioning with calcium sulfate has been investigated and found to inhibit the degradation of the fertilizer particles [2]. Another study was undertaken in which the caking of ammonium nitrate was prevented by conditioning the surfaces of the fertilizer particles with aliphatic molecules containing several carbon atoms [3]. Other compositions used to formulate such granular fertilizers include mixtures of glycerin and various minerals such as calcium and magnesium for surface conditioning to control the degradation [4]. In order to prevent the caking of the fertilizer particles, a mixture of wax and ammonium sulfate can be applied to their surfaces as a conditioning agent [5]. In particular, a recent study has found that the degradation can be prevented by applying hydrocarbons with 1-25 carbon atoms to the surfaces of urea-based fertilizer particles [6]. In addition to simple fertilizers, surface conditioning can also be performed on fertilizers with different compositions to prevent caking [7]. It has been reported that coating fertilizer particles with materials containing primary, secondary, or tertiary amine groups improves their physical properties. When a mixture of carbohydrate-based surfactants is applied to the surface of the fertilizer particles, not only do the fertilizer's properties improve, but also the activities of soil bacteria such as herbicides, insecticides, chemosterilants, nematicides, and fungicides increase [8]. Another study regarding fertilizer caking was performed by spraying a polyacrylamide solution in amounts totaling $0.05-$ $1.5 \%$ on the surfaces of the fertilizer particles, which reduced their degradation [9]. Furthermore, during a fertilizermanufacturing process involving the reaction of phosphoric acid and ammonia, the addition of $0.6 \%$ magnesium oxide positively influences the caking of the fertilizer [10]. Mixtures with various chemical compositions and their effects on the caking process have also been investigated by including more process parameters in the reaction. For example, several studies have been reported on the effects of different fertilizer particle surface morphologies on the caking process [11]. In one study, oils obtained from fatty acid alkyl esters and 


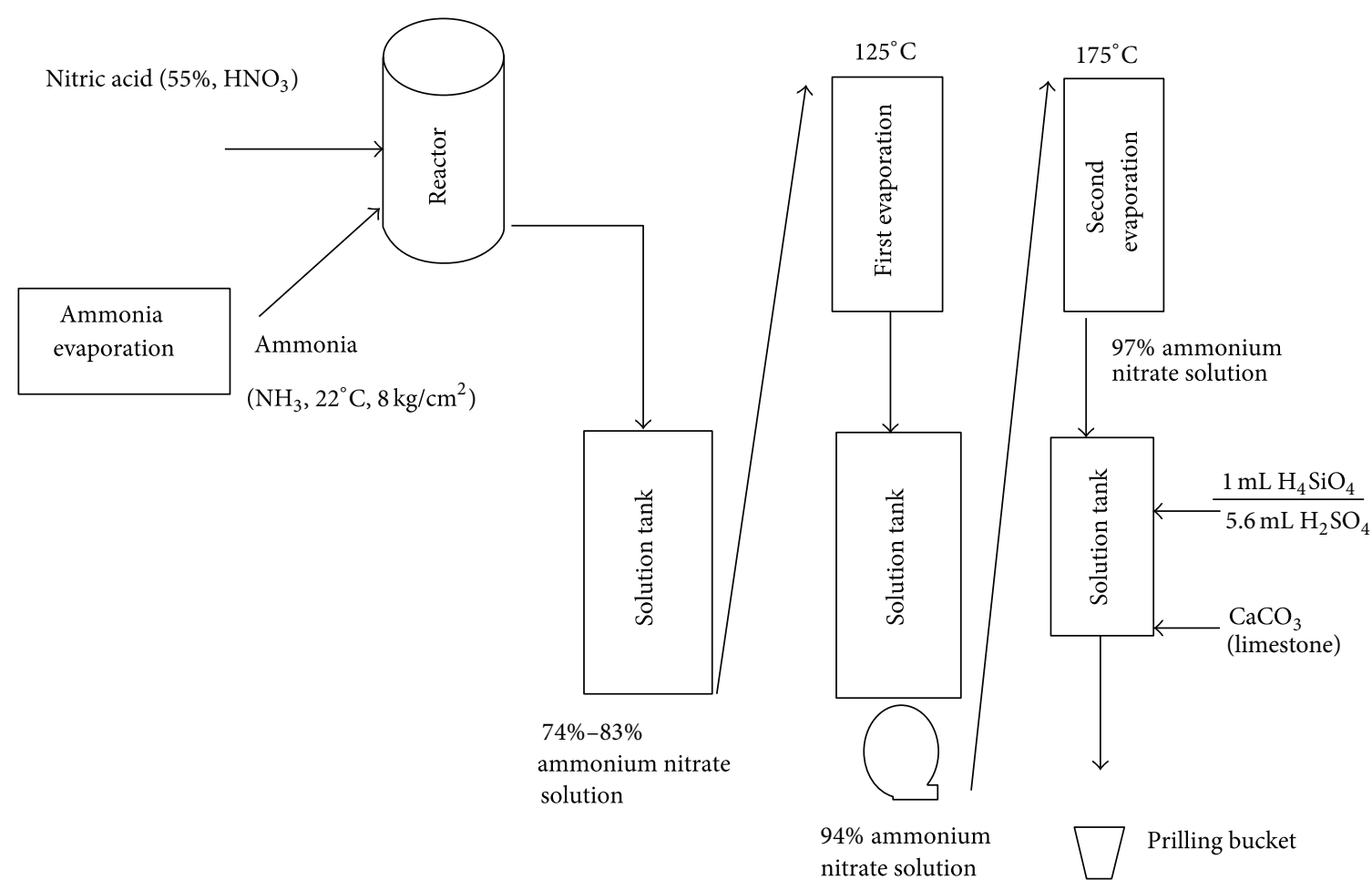

FIgURE 1: Process diagram for ammonium nitrate production.

biodiesel products were used as coating agents and were found to slow down fertilizer caking and degradation [12].

In addition to degradation of the fertilizer, its explosive properties have also been investigated. Some studies have found that degradation and explosiveness are related $[13,14]$. One method of increasing the stability of ammonium nitrate is to coat the surface of the fertilizer particles with calcium sulfate. Calcium sulfate was added to an ammonium nitrate melt in order to investigate its effect on the prill particles, namely, whether prill surfaces adhere to each other and how their surface hardness affects the fertilizer properties [1]. Some studies on decreasing the water content of the fertilizer to prevent caking have also been reported. It was found that several process parameters were important, such as the temperature, solution $\mathrm{pH}$, and reaction pressure. It has also been reported that the free-flowing characteristic of the fertilizer is closely related to its solubility in water [15]. Improved results were obtained for reactions between urea or urea-containing nitrogenous fertilizer mixtures and carbohydrates or polyvinyl compounds [16]. In addition, it was observed that the physical properties of ammonium nitrate resulted in an improved reaction between the metal silicate, containing (1\%-3\%) nitric acid, and ammonia during ammonium nitrate production [17]. In addition, improved hygroscopic properties were observed on the surfaces of fertilizer particles coated by thermosetting resins [18].

There are several methods for manufacturing ammonium nitrate, such as the Kaltenbach, Stamicarbon, SBA, ICI (nitram), C\&I Girdler, Montedison, Uhde, Fisons, and Stengel processes. In all these methods, 55\% nitric acid $\left(\mathrm{HNO}_{3}\right)$ and anhydrous ammonia react to produce ammonium nitrate. Depending on the raw materials used to dilute the ammonium nitrate and process conditions such as the temperature and pressure, these production processes present different types of difficulties [19].

Compared to previous studies performed using only a single concentration of calcium lignosulfonate, this study investigates the effects of different concentrations of calcium lignosulfonate and silicic acid on ammonium nitrate solutions along with how silicic acid consumes sulfuric acid in ammonium nitrate fertilizer.

\section{Details of the Process Used in This Study}

In the process used in this work, after the reaction between gaseous ammonia and liquid nitric acid (55\%), the water in the ammonium nitrate melt is evaporated by a two-stage evaporation system. This system is similar to the Stamicarbon process. In this system, calcium carbonate and magnesium carbonate used to dilute the ammonium nitrate solution produce carbon dioxide in the bulk ammonium nitrate, which creates foam and thus prevents prilling. Sulfuric acid is suggested to decrease the abovementioned negative effects of this processing on the fertilizer particles. In addition, silicic acid is added to the ambient reaction mixture after the evaporation (Figure 1).

\section{Experimental Details, Materials, and Methods}

Silicic acid $\left(\mathrm{H}_{4} \mathrm{SiO}_{4}\right)$, calcium lignosulfonate $\left(\mathrm{C}_{20} \mathrm{H}_{24} \mathrm{CaO}_{10} \mathrm{~S}_{2}\right)$, nitric acid $\left(\mathrm{HNO}_{3}, 55 \%\right)$, anhydrous 


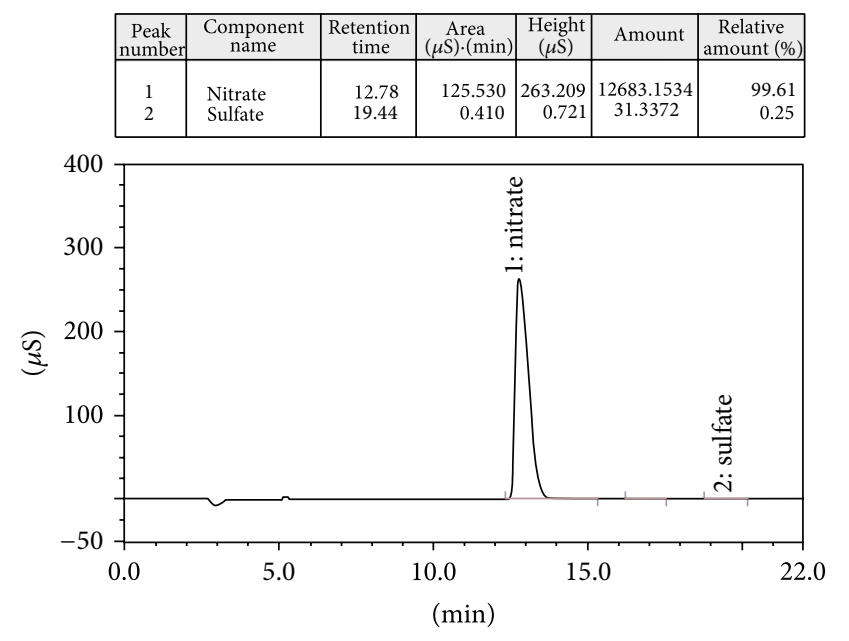

FIGURE 2: Ion chromatography for ammonium nitrate with $600 \mathrm{ppm}$ sulfuric acid.

ammonia $\left(\mathrm{NH}_{3}, 99.9 \%\right)$, and sulfuric acid $\left(\mathrm{H}_{2} \mathrm{SO}_{4}, 98 \%\right)$ were used.

Under the reaction conditions employed for the method developed in this study for the production of ammonium nitrate, anhydrous ammonia was vaporized. When the vaporized ammonia reacted with $55 \% \mathrm{HNO}_{3}$, pure ammonium nitrate was produced. To improve the physical and chemical features of the ammonium fertilizer obtained under these process conditions, calcium lignosulfonate was added. In addition, to decrease the amount of carbondioxide foam produced when calcium lignosulfonate is added to the ammonium nitrate melt, sulfuric acid (98\%) was added. Finally, to prevent the formation of double salts due to this added sulfuric acid, which causes degradation and caking, silicic acid was also added.

The concentrations of calcium lignosulfonate added during the process were $0.05 \%, 0.07 \%, 0.1 \%, 0.15 \%, 0.17 \%$, and $0.19 \%$. Furthermore, $1 \mathrm{~mol}$ silicic acid/5.6 $\mathrm{mol} \mathrm{H}_{2} \mathrm{SO}_{4}$ was included as a second additive. $\mathrm{H}_{2} \mathrm{SO}_{4}$, which is required in the fertilizer production process, was added in a concentration of $600 \mathrm{ppm}$.

3.1. Ion Chromatography Analysis. To detect the amounts of anions and cations of ammonium nitrate, ion chromatography was performed according to ASTM E1151-93 [20] (Figures 2 and 4) with a Shimadzu Prominence HIC-NS, which has a measuring accuracy of $0.1-5120 \mu \mathrm{m} \mathrm{Scm}^{-1}$ and a flow rate control range of $0.001-5 \mathrm{~mL} / \mathrm{min}$.

3.2. Electron Microscopy Analysis. Electron microscopy was performed to investigate how calcium lignosulfonate, silicic acid, and sulfuric acid affect the fertilizer surface according to ASTM E986-97 [21] (Figures 3, 5, 6, and 7). For this analysis, a Carl Zeiss DSM-960A scanning electron microscope was used. The technical properties of this electron microscope are as follows: accelerating voltage, $1,000-30,000 \mathrm{~V}$; useful magnification, $\times 10-\times 30,000$; and resolution, $70 \AA$.

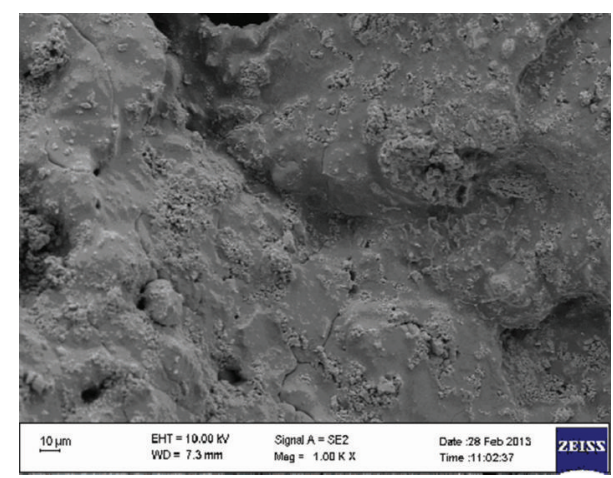

FIGURE 3: SEM image of ammonium nitrate with $600 \mathrm{ppm}$ sulfuric acid.

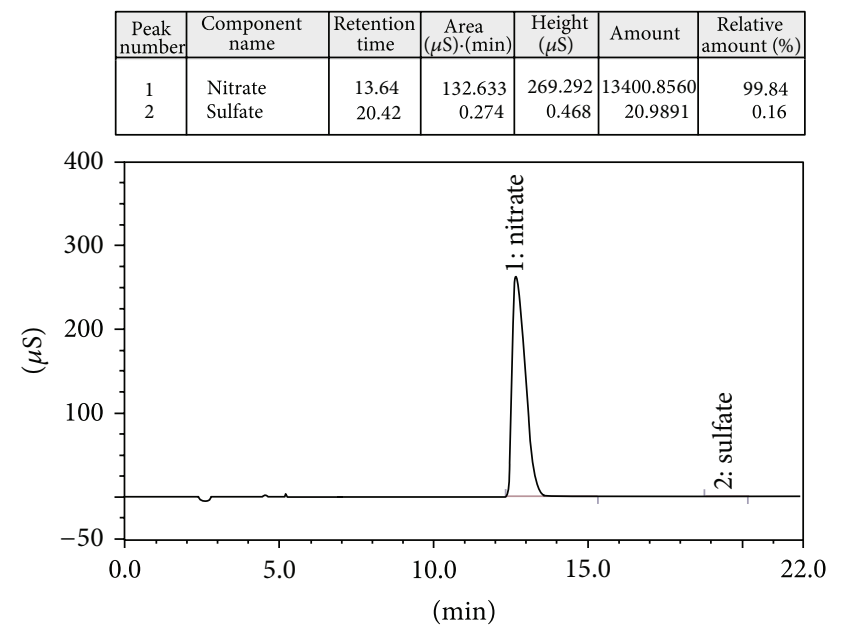

FIGURE 4: Ion chromatography for ammonium nitrate with $1 \mathrm{~mL}$ $\mathrm{H}_{4} \mathrm{SiO}_{4} / 5.6 \mathrm{~mL} \mathrm{H}_{2} \mathrm{SO}_{4}$.

3.3. Screen Sieve Analysis. Fertilizer prills containing silicic acid, sulfuric acid, and calcium lignosulfonate were stored between 3 and 6 months (Table 1) and then subjected to screening analysis with a Vibratory Sieve Shaker AS 200 according to the ASTM E11-09 standard [22].

\section{Results and Discussion}

At present, the "vacuum concentration method" is commonly used for the production of ammonium nitrate. In this process, the water in ammonium nitrate melts is removed by vacuum. However, this requires high equipment costs, and so various chemical compositions have been suggested to minimize the production cost.

In the available literature, some chemical additives have been suggested to completely prevent fertilizer caking when they are applied on the outer surface of the fertilizer particles, which ensures that the fertilizer particles do not adsorb the surrounding moisture. On the other hand, several chemicals are also used as internal additives. As in such reports in the literature, in this study, the chemicals proposed are used as both internal additives and external additives. This study 
TABLE 1: Screening analysis after three months and six months.

\begin{tabular}{lccccccc}
\hline Period (months) & $3.35 \mathrm{~mm}(\%)$ & $2.5 \mathrm{~mm}(\%)$ & $2.0 \mathrm{~mm}(\%)$ & $1.0 \mathrm{~mm}(\%)$ & $0.5 \mathrm{~mm}(\%)$ & E.A. mm (\%) & Crushing strength (kg/prill) \\
\hline After three months & 4.6 & 49.3 & 37.6 & 7.8 & 0.7 & 0 & 2.27 \\
After six months & 5.2 & 45.0 & 38.6 & 10.4 & 0.8 & 0 & 2.15 \\
\hline
\end{tabular}

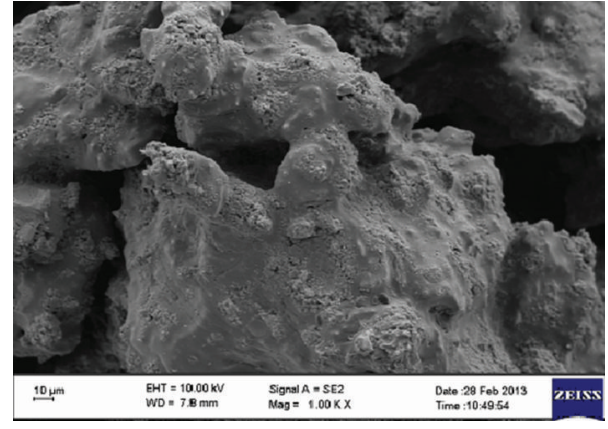

FIGURE 5: SEM image of ammonium nitrate with $1 \mathrm{~mL}$ $\mathrm{H}_{4} \mathrm{SiO}_{4} / 5.6 \mathrm{~mL} \mathrm{H}_{2} \mathrm{SO}_{4}$.

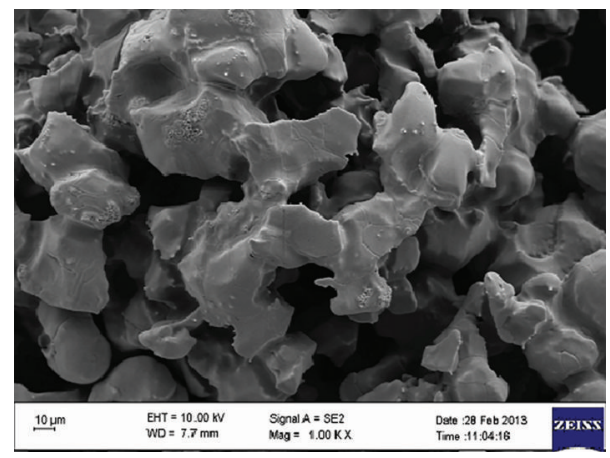

FIGURE 6: SEM image of ammonium nitrate with $1 \mathrm{~mL}$ $\mathrm{H}_{4} \mathrm{SiO}_{4} / 5.6 \mathrm{~mL} \mathrm{H}_{2} \mathrm{SO}_{4}$ and $0.1 \%$ calcium lignosulfonate.

investigates the adhesion of the chosen chemicals to the surface of the fertilizer particles and their effect on the chemical properties of the fertilizer. The improved nutriment properties are also investigated.

The chemical reagents used as external additives act as coating agents on the surfaces of the fertilizer particles and thus act to condition the surface. The coating also suppresses the explosive nature of the organic compound.

To improve the chemical properties of the fertilizer used in this study, calcium lignosulfonate $\left(\mathrm{C}_{20} \mathrm{H}_{24} \mathrm{CaO}_{10} \mathrm{~S}_{2}\right)$ was added into the ambient reaction solution. Lignosulfonates are a waste product of paper, and raw lignosulfonates can be converted to chemical reagents by various chemical reactions. Depending on the wood source, various lignosulfonates can be produced [23]. For example, normal fluidized lignosulfonates and modified lignosulfonates that act as super fluids have been developed and produced [24]. Furthermore, several metal ions $\left(\mathrm{Ca}^{2+}, \mathrm{Na}^{+}, \mathrm{Mg}^{2+}, \mathrm{K}^{+}, \mathrm{Fe}^{2+}, \mathrm{Cu}^{2+}, \mathrm{Zn}^{2+}\right.$, $\mathrm{Ni}^{2+}$, and $\mathrm{Al}^{3+}$ ) can form compounds with lignosulfonates. The most common compounds used are calcium and sodium

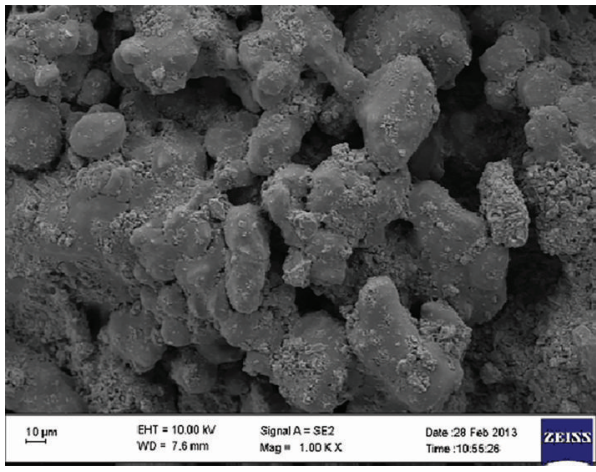

FIGURE 7: SEM image of ammonium nitrate with $0.1 \%$ calcium lignosulfonate.

lignosulfonate. The main function of lignosulfonate is to facilitate the fertilizer movement by softening the fertilizer particles. Lignosulfonates also decrease the surface tension, and so they can be easily adsorbed on a material's surface. Because fertilizer particles have similar electrostatic charges, they repel each other. Therefore, particle aggregation is prevented, and a homogeneous material is formed. Another effect of decreasing the surface tension is to cause air to be incorporated into the material. Stabilized air bubbles are useful for processing, but they may also decrease the crushing strength of the fertilizer particles. The amount of lignosulfonates adsorbed on the surfaces of fertilizer particles increases with the increasing molecular weight of the lignosulfonates [25].

In order to increase the nutrient value of the fertilizer in the soil, different concentrations of calcium lignosulfonate, which provides nutrient value because of its organic structure, were added for surface conditioning, and the physical effects were investigated.

Calcium lignosulfonate was added using two different methods in this study. For the first experiment, calcium lignosulfonate was introduced into the ammonium nitrate solution as an internal additive in the first evaporation stage in concentrations of $0.05 \%, 0.07 \%, 0.1 \%, 0.15 \%, 0.17 \%$, and $0.19 \%$ by weight. For the second experiment, calcium lignosulfonate was introduced as an external additive in the same six concentrations $(0.05 \%, 0.07 \%, 0.1 \%, 0.15 \%, 0.17 \%$, and $0.19 \%$ by weight) and as a coating agent on the fertilizer surface. Excellent strength results were observed (Table 1) in the screen sieve analysis when calcium lignosulfonate was used as an internal additive; further, calcium lignosulfonate adheres well to the fertilizer surface when used as an external additive. In addition to these desirable properties, this material is inexpensive. For these reasons, $0.1 \%$ calcium lignosulfonate is selected as the optimum concentration for both internal and external additive experiments. Therefore, ion chromatography, scanning electron microscopy, and 
screen sieve analysis were performed for a $0.1 \%$ (by weight) calcium lignosulfonate concentration.

Silicic acid $\left(\mathrm{H}_{4} \mathrm{SiO}_{4}\right)$ and sulfuric acid $\left(\mathrm{H}_{2} \mathrm{SO}_{4}, 98 \%\right.$ (by weight)) were added as internal additives because of their liquid phases. Because the fertilizer prills have been dried, these liquid additives cannot be applied to the fertilizer surfaces after prilling.

Six different concentrations of calcium lignosulfonate were added and their effects on fertilizer degradation were observed under a pressure of $0.28 \mathrm{~kg} \cdot \mathrm{cm}^{-2}$. For the second experiment, calcium lignosulfonate was applied to the surface of the fertilizer particles in a concentration equal to the average value of these six concentrations, and the degradation was investigated under the same pressure.

In the ammonium nitrate production procedure used in the present study, after the reaction between anhydrous ammonia and nitric acid is carried out, a dilute solution of calcium carbonate is added to the ambient reaction. Along with calcium carbonate, carbon dioxide is generated in solution. In an ammonium nitrate production plant, sulfuric acid is added to react with carbon dioxide (Figures 2 and 3 ). Thus, some sulfate salts are produced in the ammonium nitrate bulk during storage, which cause caking problems [2]. In this study, silicic acid is added to the ambient reaction medium as an internal additive to react with sulfuric acid and decrease the occurrence of sulfate salts in the bulk ammonium nitrate.

For some applications, special reagents are added to increase the scope of the Kjeldahl method. The most commonly used reagents are sodium thiosulfate and silicic acid, which can be added to consume and quantify the sulfuric acid present. This modern technique is in contrast to previously reported systems based on the quantification of nitrates and nitrites. Silicic acid $\left(\mathrm{H}_{4} \mathrm{SiO}_{4}\right)$ decomposes into carbon dioxide and water when it reacts with sulfuric acid. During this process, $1 \mathrm{~mL}$ of silicic acid consumes $5.6 \mathrm{~mL}$ of sulfuric acid [26].

After the addition of silicic acid, the amount of sulfate ions was investigated by ion chromatography (Figure 4) and electron microscopy (Figure 5). It is understood from the results that silicic acid decomposes to carbon dioxide and water when it reacts with sulfuric acid. During this process, $1 \mathrm{~mL}$ of silicic acid consumes $5.6 \mathrm{~mL}$ of sulfuric acid.

During operation, to gauge the effects of the chemical reagents on the fertilizer particles, each chemical reagent is investigated separately. Accordingly, sulfuric acid is added as the main compound in the applied process. Calcium lignosulfonate and silicic acid, added separately at predetermined concentrations, were the other chemical reagents whose effects were investigated; their corresponding effects on the ambient reaction were investigated by ion chromatography and electron microscopy.

After ammonium nitrate fertilizer is produced, electron microscopy and screen sieve analysis, in addition to ion chromatography, were performed to investigate the surface and physical properties of the fertilizer under storage conditions.

The purpose of ion chromatography is to understand the changes in the cations and anions present in the fertilizer and to observe the consumption of sulfuric acid by silicic acid. As seen in Figures 2 and 4, when silicic acid is added to the reaction mixture, the amount of sulfate ions produced from sulfuric acid decreases. Because sulfuric acid plays an important role in the formation of double salts (such as nitrate and sulfate salts), ion chromatography was performed after the addition of both silicic acid and sulfuric acid.

For the electron microscopy experiments, $600 \mathrm{ppm}$ sulfuric acid $\left(\mathrm{H}_{2} \mathrm{SO}_{4}\right.$; Figure 3), $1 \mathrm{~mL} \mathrm{H}_{4} \mathrm{SiO}_{4} / 5.6 \mathrm{~mL} \mathrm{H}_{2} \mathrm{SO}_{4}$ (Figure 5), and $0.1 \%$ of calcium lignosulfonate (Figure 6 ) were added to the fertilizer solution. Because of these additions, the surface area of the fertilizer was found to increase and its degradation rate was observed to decrease. Scanning electron microscopy was performed for all samples with different additives to observe the surface changes in the fertilizer.

From the screening analyses, it was observed that the under-sieve ratio used to evaluate the degradation was not affected by storage. Furthermore, the sieve analysis results for samples taken from any point in the bulk fertilizer solution were close to each other (Table 1).

As seen in the ion chromatography results, during storage, sulfuric acid-containing fertilizer produced with silicic acid in the process is more stable than the fertilizer produced with no silicic acid. Finally, from the screening analysis, it was determined that the use of silicic acid in the process decreases the tendency of the fertilizer to degrade (Table 1). When calcium lignosulfonate is added to the reaction, the physical properties are not further improved over those of the fertilizer with silicic acid (Figure 7).

\section{Conclusions}

In this study, the effects of process conditions on physical problems such as fertilizer degradation and caking were investigated. The results showed that, by using various mixtures of different chemical compounds, it is possible to improve the physical properties of ammonium nitrate fertilizer particles.

In both laboratory experiments and process operation, it was observed that calcium lignosulfonate and silicic acid could be used as nutrient sources to improve the free-flowing characteristics of the fertilizer and as a solution additive to resolve the problems of degradation and caking. According to the instrumental analysis in this study, these results are an improvement over the properties found in current reports available in the literature. According to these results, the optimum concentrations are $0.1 \%$ calcium lignosulfonate, $1 \mathrm{~g} / 5.6 \mathrm{~mL}$ silicic acid $\left(\mathrm{H}_{4} \mathrm{SiO}_{4}\right) /$ sulfuric acid $\left(\mathrm{H}_{2} \mathrm{SO}_{4}\right)$, and 600 ppm sulfuric acid $\left(\mathrm{H}_{2} \mathrm{SO}_{4}\right)$.

\section{Conflict of Interests}

The authors declare that there is no conflict of interests regarding the publication of this paper.

\section{References}

[1] G. F. Malash and H. M. Hashem, "Improving the properties of ammonium nitrate fertilizer using additives," Alexandria Engineering Journal, vol. 44, no. 4, pp. 685-693, 2005. 
[2] H. Kiiski, M. Lylykangas, R. J. Milborne, and J. Poukari, "Ammonium nitrate granule and method for the preparation of the same," US Patent 8110018 B2, 2012.

[3] A. J. R. Martínez and M. R. Fajardo, "Anti-caking compositions for fertilizers," Patent WO2009004024A2, 2010.

[4] M. Ogzewalla, "Dust control of solid granular materials," US Patent 20080072641 A1, 2008.

[5] D. A. Burlone, J. Easterling, J. R. Garner, P. R. Meiller, and R. M. Sink, "Apparatus for treating particles," Patent WO2007104661A1, 2008.

[6] E. A. Bijpost, L. Vanmarcke, J. G. Korver, and R. V. Belzen, "Method of improving the properties of urea granules," US Patent 8343891 B2, 2013.

[7] M. Krysiak and D. Madigan, “Granular fertilizer," US Patent 20040069032 Al, 2004.

[8] R. T. Walker, "Surfactant coated products and methods for their use in promoting plant growth and soil remediation," US Patent 6565860 B1, 2003.

[9] M. Brigance and G. McManic, "Free flowing fertilizer composition with enhanced deposition/anti drift characteristics," US Patent 20020006874 A1, 2002.

[10] D. Clark and L. Peacock, "Process for manufacturing fertilizer," US Patent 20030110821 A1, 2003.

[11] J. D. Eastham, N. P. Wynnyk, and B. Xing, "Process and apparatus for producing a coated product," US Patent 8178161 B2, 2012.

[12] T. C. Arnst, D. L. Kouznetsov, P. C. Miller, and B. L. Tran, "Coating oil comprising byproducts from the manufacture of fatty acid alkyl esters and/or biodiesel," Patent WO 2008100921 A3, 2008 .

[13] H. Hero and M. Lylykangas, "Ammonium nitrate granules," US Patent 8157935B2, 2012.

[14] R. R. Pille and F. C. Visagie, "Fertilizer granules and manufacturing process thereof," US Patent 8137431 B2, 2012.

[15] A. Yosef, Y. Oren, and Y. Yagil, "Soluble and solubilizing, free-flowing, solid fertilizer compositions, and the preparation thereof," US Patent 7967889 B2, 2011.

[16] R. V. Belzen and L. Vanmarcke, "Method of improving the crushing strength and reducing the dust formation and the caking tendency of urea, and urea composition," US Patent 7816561 B2, 2010.

[17] H. Hero and J. Poukari, "Stabilized ammonium nitrate granules," US Patent 7147830 B2, 2006.

[18] N. Tabei, "Granular coated fertilizer," US Patent 7018441 B2, 2006.

[19] United Nations Industrial Development Organization, Process Technologies for Nitrogen Fertilizers, vol. 9 of Development and Transfer of Technology, United Nations, New York, NY, USA, 1978.

[20] ASTM Standard E1151-93, Standard Practice for Ion Chromatography Terms and Relationships, ASTM International, West Conshohocken, Pa, USA, 2011.

[21] ASTM Standard E986-97, Standard Practice for Scanning Electron Microscope Beam Size Characterization, ASTM International, West Conshohocken, Pa, USA, 1997.

[22] ASTM Standard E11-09, Standard Specification for Wire Cloth and Sieves for Testing Purposes, ASTM International, West Conshohocken, Pa, USA, 2009.

[23] J. R. G. Bryce, "Sulfite pulping," in Pulp and Paper: Chemistry and Chemical Technology, J. P. Casey, Ed., pp. 291-376, WileyInterscience, New York, NY, USA, 1980.
[24] Z. Zhor and T. W. Bremner, "Influence of lignosulfonate molecules on the properties of fresh concrete," in Proceedings of the International Conference on Super Plasticizers and Other Chemical Admixtures in Concrete, vol. 173, pp. 781-806, ACISP, Rome, Italy, 1997.

[25] O. Stránil and T. Sebök, "Relationships between the properties of ligninsulphonates and parameters of modified samples with cement binders: part III. Determination of sulphonated compounds content, characteristic of sulphonation, sorption studies," Cement and Concrete Research, vol. 29, no. 11, pp. 17691772, 1999.

[26] J. Persson, M. Wennerholm, and S. O'Halloran, Handbook for Kjeldahl Digestion, Foss Publishing, Hillerød, Denmark, 4th edition, 2008. 

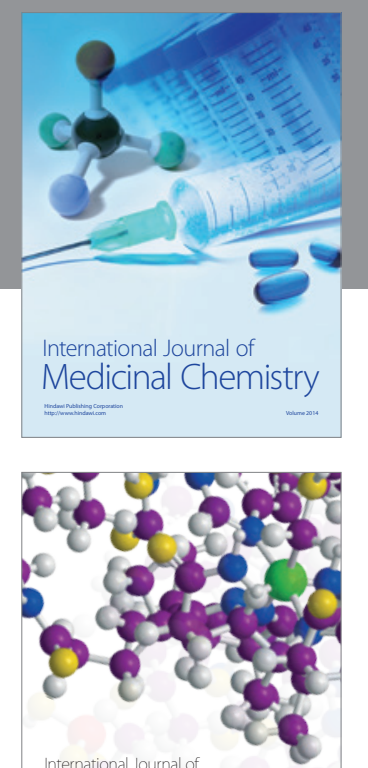

\section{Carbohydrate} Chemistry

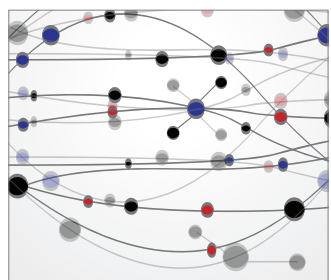

The Scientific World Journal
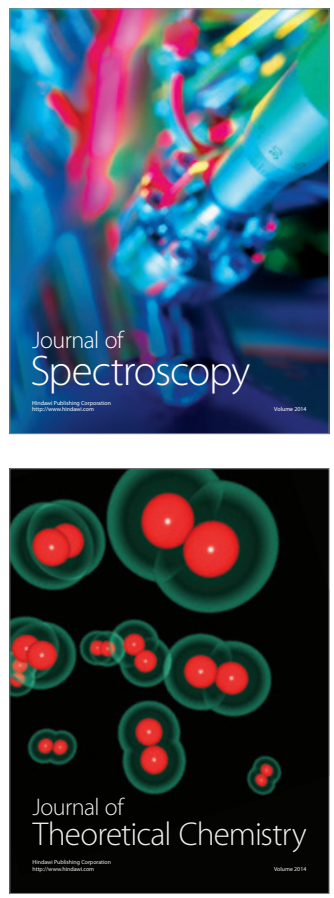
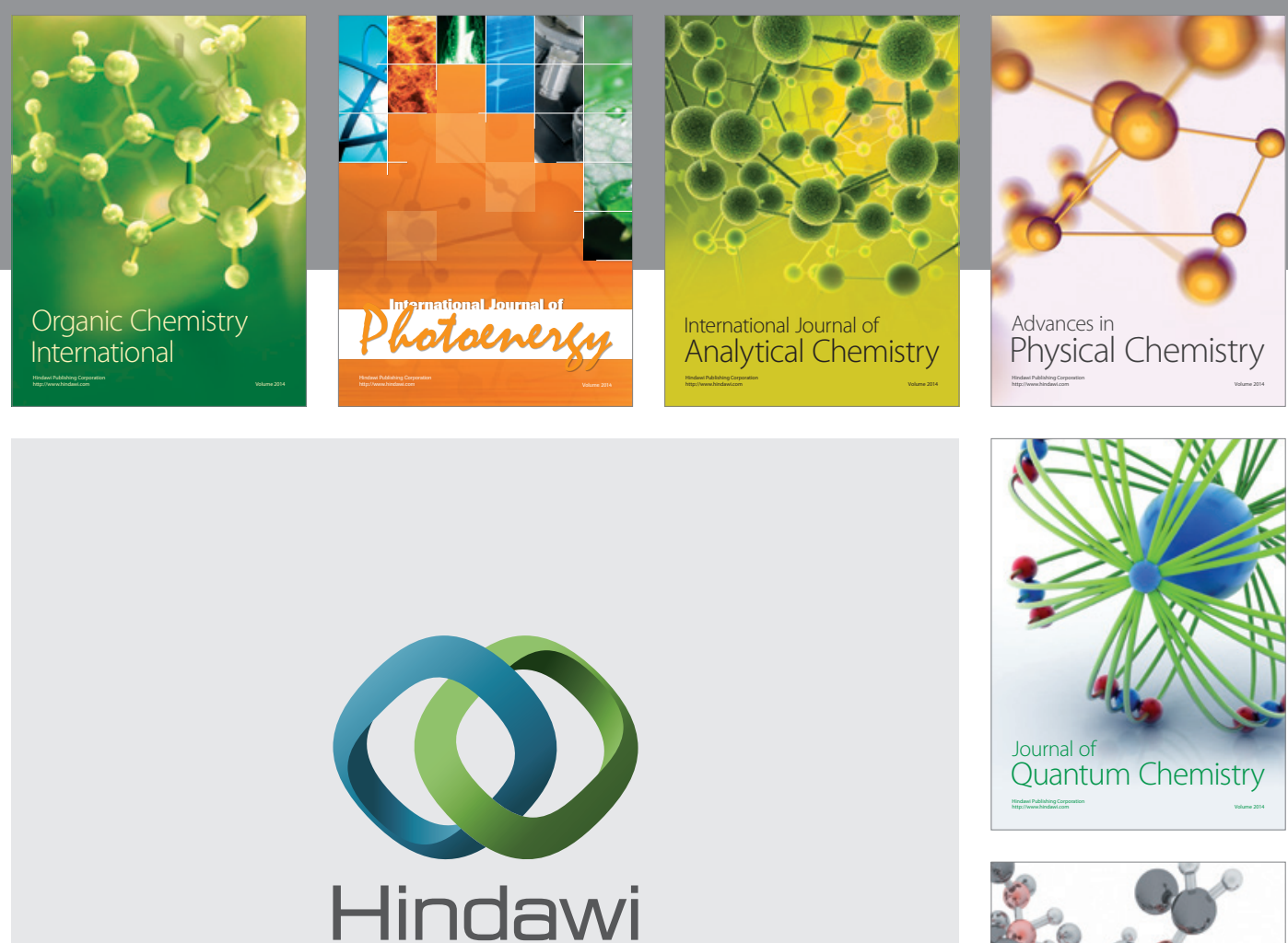

Submit your manuscripts at

http://www.hindawi.com

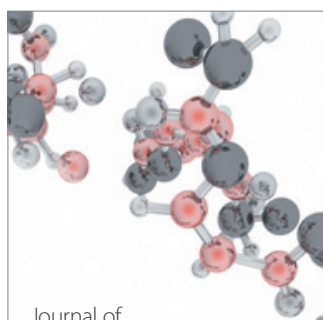

Analytical Methods

in Chemistry

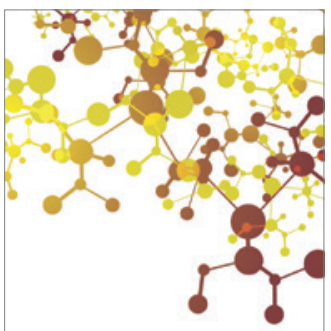

Journal of

Applied Chemistry

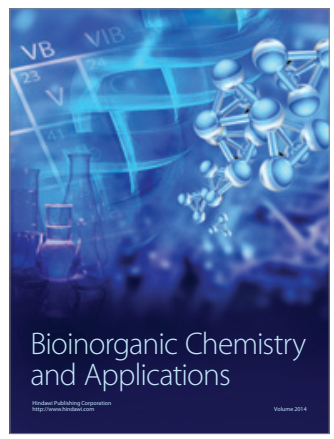

Inorganic Chemistry
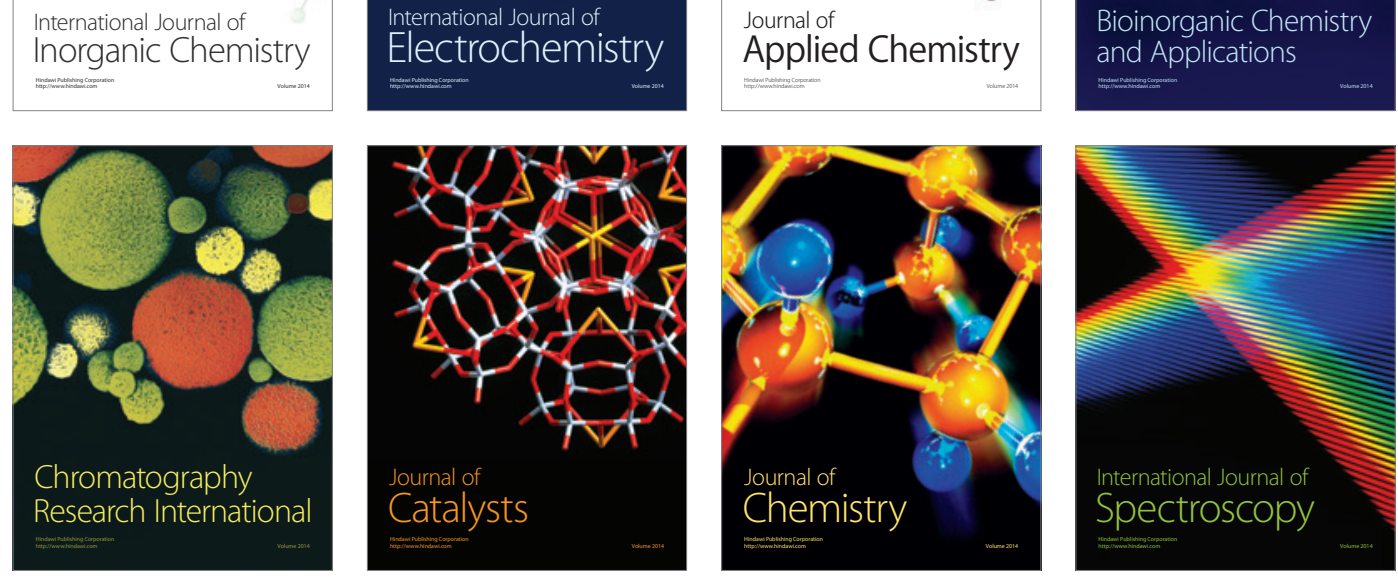